1 Balancing biodiversity outcomes and pollution management in urban stormwater treatment wetlands

3 Robin Hale $^{1^{*}}$, Stephen E Swearer ${ }^{1}$, Michael Sievers ${ }^{1,+}$, Rhys Coleman $^{2,3}$

$4 \quad{ }^{1}$ School of BioSciences, University of Melbourne, Parkville, Victoria, Australia 3010

$5 \quad{ }^{2}$ Melbourne Water Corporation, Docklands, Victoria, Australia 3008

$6{ }^{3}$ School of Ecosystem and Forest Sciences, University of Melbourne, Parkville, Victoria,

7 Australia 3010

$8 \quad *$ Email: robin.hale@unimelb.edu.au

$9+$ Current address: Australian Rivers Institute, Griffith University

\title{
11 Role of the funding source
}

12 We acknowledge funding from the Australian Research Council (LP140100343) and

13 Melbourne Water. R. Coleman is an employee of Melbourne Water and contributed to

14 the development and preparation of the article, and the decision to submit for publication.

16 Competing interests

17 We have no conflict of interest to declare. 
Abstract

Wetlands are increasingly being constructed to mitigate the effects of urban

stormwater, such as altered hydrological regimes and reduced water quality, on downstream aquatic ecosystems. While the primary purpose of these wetlands is to manage stormwater, they also attract animals whose growth, survival and breeding (i.e. 'fitness') may be compromised. Such deleterious effects will be exacerbated if animals are caught in 'ecological traps', mistakenly preferring wetlands with unsuitable environmental conditions. Alternatively, wetlands that offer suitable habitat conditions for animals could be beneficial, especially in fragmented urban landscapes. Consequently, a thorough understanding of the potential ecological impacts of stormwater treatment wetlands is critical for managing unintended consequences to urban biodiversity.

To help facilitate this understanding, we draw upon findings from a four-year research program conducted in the city of Melbourne in south-eastern Australia as a case study. First, we summarise our research demonstrating that some stormwater wetlands can be ecological traps for native frogs and fish in the study region, whilst others likely provide important habitat in areas where few natural waterbodies remain. We use our work to highlight that while stormwater wetlands can be ecological traps, their effects can be properly managed.

We propose the need for a better understanding of the ecological consequences of changes to wetland quality and their population-level impacts across the landscape. We hope that this study will generate discussions about how to most effectively manage constructed wetlands in urban landscapes and more research for a better understanding of the issues and opportunities regarding potential ecological traps.

Keywords: animal behaviour, ecological trap, urban planning, water sensitive urban design 
In $2015,54 \%$ of the world's population lived in urban areas, and this is predicted to be closer to $70 \%$ by 2050 (WHO, 2017). The development of infrastructure to support this growth places considerable demand on aquatic ecosystems (Chin, 2006), and changes the nature and distribution of wetlands around cities (Kentula et al., 2004). Urbanisation causes a raft of effects on the biological, chemical and physical characteristics of aquatic environments (Walsh et al., 2005). One of the major changes is an increase in stormwater runoff from impervious surfaces (e.g. roads, buildings) connected to waterways. Stormwater runoff can alter the hydrological regime in receiving waters with subsequent impacts to stream geomorphology (Vietz et al., 2016b), and contain a diverse range of pollutants (e.g. nutrients, metals, herbicides and hydrocarbons: Malaviya and Singh, 2012).

One of the most common methods to manage the impact of urban run-off on receiving environments is to construct stormwater treatment wetlands (Malaviya and Singh, 2012), with tens of thousands of these built in residential, commercial and industrial urban areas throughout the world (Tixier et al., 2011). These wetlands have been shown to effectively treat pollutants in stormwater both in specific case studies (e.g. Al-Rubaei et al., 2017; Schulz et al., 2003) and more general assessments (e.g. for the UK; Lucas et al., 2015). Although not the primary function of these treatment systems, it is common for animals to colonise stormwater wetlands (Hassall and Anderson, 2015; Tixier et al., 2011). In some circumstances, stormwater treatment wetlands can be important habitats (e.g. Holtmann et al., 2018; Holtmann et al., 2017), especially since one of the major challenges facing animals in urban landscapes is habitat loss and fragmentation. Recognising the importance of unconventional habitats like these wetlands may be an important component of urban biodiversity conservation (Soanes et al., In press). 
Urban stormwater wetlands can suitable habitats for some animals, with comparable

biodiversity and community structure to natural lakes (Stephansen et al., 2016). While the pollutants that accumulate as part of the stormwater treatment function may not have deleterious effects on some species (Søberg et al., 2016), they have the potential to cause a range of lethal and sub-lethal effects for others. For instance, experiments in the US have shown that exposure to pond sediments with elevated heavy metal and salt concentrations can kill frog embryos, and cause sub-lethal effects such as reduced size at metamorphosis in other species (Gallagher et al., 2014; e.g. Snodgrass et al., 2008). A recent global assessment indicated that while measures of abundance and species richness in stormwater wetlands can be comparable to natural wetlands, the fitness (i.e. growth, survival, reproduction) of animals is often decreased (Sievers et al., 2018a). There appears to be a conflict between the engineered purpose of these wetlands as stormwater treatment systems, and their incidental use as habitats by wildlife.

Understanding the potential ecological costs and benefits of urban stormwater wetlands depends on knowledge about how the presence and fitness of animals that inhabit them varies. If poor fitness outcomes are associated with occupying certain wetlands, the consequences will be exacerbated if animals do not avoid these habitats. From an evolutionary perspective, animals should choose habitats where their fitness is high, but some mistakenly choose habitats where their fitness is reduced - a situation known as an ecological trap (Robertson and Hutto, 2006). Many animals use indirect cues associated with likely future habitat quality to select habitats (e.g. birds use vegetation to predict future food resources or predator densities; Cody, 1985). Ecological traps arise when these cues are poor predictors of habitat quality (Robertson and Chalfoun, 2016; Robertson and Hutto, 2006; Robertson et al., 2013). Perhaps the clearest example of an ecological trap is when insects are 
attracted to polarised light reflected from artificial surfaces (e.g. street lamps, sides of buildings, roads) (Horvath, 1995; Horvath et al., 1998).

Ecological traps can also arise as unintended consequences of management activities and pose a serious but largely unexplored conservation risk (Battin, 2004; Hale et al., 2015a; Hale and Swearer, 2017). Traps could cause local extinctions if animals that colonise them are unable to breed or survive. Traps may also increase the risk of regional extinction by attracting animals away from high quality sites and into those where their fitness is reduced (Hale et al., 2015b).

There is a strong conceptual basis for predicting that some stormwater wetlands are ecological traps given the potential conflict between their intended stormwater treatment purpose and their use by animals (Hale et al., 2015a; Tilton, 1995). There has, however, been limited work examining how urban stormwater treatment wetlands function as habitats for animals, and less on whether they are ecological traps. Being able to identify wetlands where animals have low fitness and especially those that are traps is critical if impacts to susceptible animals are to be managed. It is equally important to know where high quality wetlands occur to help target conservation and management efforts, since these wetlands may enhance connectivity and increase biodiversity in urban areas where few natural waterbodies remain.

It may be possible to plan management activities to prevent ecological traps arising in the first place, but in instances when ecological traps have arisen as unintended consequences of management actions there are several steps to identify and mitigate their impact (Hale et al., 2015a). The first step is to assess the risks that management activities pose to animals (e.g. how will environmental conditions change and where will changes take place relative to the distribution of animals) and implementing preventative measures such as alternative treatment systems that are less likely to attract animals (e.g. biofilters, raingardens, rainwater 
tanks) or providing off-line habitat more suitable for animals. The second step involves

117 testing if an ecological trap has formed, requiring information about how the fitness of animals is affected by habitat changes, and the habitat preferences of animals (Robertson and Hutto, 2006). If an ecological trap has formed, the third step is to mitigate its effects. This could involve improving habitat quality (e.g. remediating sediments to reduce pollutant of vegetation). landscapes. how stormwater wetlands might perform as habitats for animals for several reasons. First, as 
substantial, from fewer than 50 in the mid-1980s to over 700 currently (Hale et al., 2015a; Sharley et al., 2017). Therefore, stormwater wetlands are a major feature of the landscape, and one of the most common habitats available for animals. Second, animals are found in these wetlands (e.g. Murray et al., 2013). Third, wetlands range considerably in terms of their likely habitat quality for animals, and many have sediment pollutant concentrations that are above published sediment quality guidelines e.g. heavy metals (Sharley et al., 2017) and pesticides (Allinson et al., 2015). Stormwater wetlands in Melbourne have also been built in areas with a diverse range of land uses including rural, urban growth, residential, industrial and commercial. We therefore predicted that animals could inhabit some locations that are potentially suitable habitats but also others (e.g. those that are highly polluted) where deleterious impacts on fitness are likely.

\subsection{Are stormwater wetlands ecological traps for native frogs?}

Stormwater pollutants can impact amphibians by reducing survival and impairing growth (Gallagher et al., 2014; Snodgrass et al., 2008), causing physical abnormalities (Reeves et al., 2010) and changing behaviour (Moore et al., 2015). We surveyed amphibian assemblages at 67 urban wetlands spanning gradients in pollutant concentrations, to determine if frogs were found in highly polluted wetlands where they likely suffer fitness costs (Sievers et al., In press). The presence of most frog species was related to emergent and fringing vegetation, which is consistent with surveys from other urban ponds in the region (Hamer and Parris, 2011), but contaminant levels were largely unimportant. Frogs readily inhabited wetlands with concentrations of heavy metals and pesticides capable of causing lethal- and sub-lethal effects (Sievers et al., 2018b; Sievers et al., In press; Sievers et al., 2018c). 
Our surveys highlighted that some stormwater wetlands may be ecological traps for frogs, so we experimentally tested if this was the case (Sievers et al., 2018c), focussing on a species that commonly breeds in urban wetlands, the spotted marsh frog (Limnodynastes tasmaniensis) (Ficken and Byrne, 2013; Hamer and Parris, 2011). We tested if survival and metamorphosis-related measures of frogs differed within mesocosms that simulated six wetlands with different contaminant levels, and if tadpoles raised in more contaminated conditions were less able to avoid cues from predators in laboratory trials. We paired this work with a field-based oviposition (egg laying) experiment to assess breeding-site preferences. Our results showed that stormwater wetlands can be ecological traps for frogs: survival was lower and tadpoles were less responsive to predator cues when raised in polluted conditions, but adults laid equivalent numbers of eggs across wetlands (Sievers et al., 2018c).

Animals often respond to environmental changes by altering their behaviour, which can determine how they cope in changing environments (Tuomainen and Candolin, 2011; Wong and Candolin, 2015). Behaviour can be directly linked to fitness, especially in terms of behavioural responses to contaminants (Zala and Penn, 2004) and might serve as a sensitive 'early warning' indicators of deleterious effects (Zala and Penn, 2004). In addition, animals are likely to experience multiple contaminants simultaneously, and determining how these potential stressors interact to impact behaviour is critical to understanding responses under natural conditions (Hale et al., 2017; Halfwerk and Slabbekoorn, 2015). We exposed spotted marsh frog tadpoles to two pollutants, copper and imidacloprid, at concentrations observed in wetlands around Melbourne (Allinson et al., 2015), and conducted laboratory choice experiments to document responses to predator olfactory (sense of smell) cues and tail prodding (simulated 'attack'). Imidacloprid is a neonicotinoid insecticide and whereas exposure to other neurotoxic insecticides can affect amphibian behaviour (Brunelli et al., 2009), its effects on frogs have not been investigated. We found (Sievers et al., 2018b) that 
tadpoles suffered high mortality rates when exposed to imidacloprid, and that only tadpoles that were not exposed to either contaminant avoided predator cues. In addition, imidacloprid and copper interacted to increase rates of erratic swimming, and exposed tadpoles were less able to escape simulated attacks. Collectively, we have shown that frogs are found in many stormwater treatment wetlands across Melbourne that vary in terms of the level of pollutants that are present, and that some wetlands are likely ecological traps for spotted marsh frogs.

\subsection{Are stormwater wetlands ecological traps for native fish?}

We tested if stormwater wetlands can be ecological traps for a native fish, the dwarf galaxias (Galaxiella pusilla), which is listed as vulnerable on both the IUCN Red List (IUCN, 2015) and the Australian Environment Protection and Biodiversity Conservation Act 1999. G. pusilla is a small (generally $<40 \mathrm{~mm}$ ) fish native to south-eastern Australia that occurs in slow-flowing or still, shallow habitats (e.g. swamps, drains, backwaters, wetlands) often containing dense macrophytes and emergent plants (Coleman, 2014; Coleman et al., 2015). Habitat loss and invasive species are identified as major threats (Saddlier et al., 2010). We examined habitat selection behaviour of G. pusilla, using laboratory choice experiments to show that fish were not responsive to a range of cues (e.g. from conspecifics or vegetation), and did not avoid water from stormwater wetlands (Hale et al., 2018). However, in a field experiment, survival was lower at stormwater wetlands than paired, nearby non-stormwater sites, and fish suffered delayed ovarian maturation, potentially due to a lack of food (zooplankton). We also conducted a series of additional laboratory and field experiments to examine the effects of the invasive mosquitofish (Gambusia holbrooki), which commonly occurs with G. pusilla (Coleman et al., 2017) and has been linked to the decline of numerous native fish and amphibians (Pyke, 2008). We found that G. holbrooki heavily predated $G$. pusilla larvae, and disrupted adult spawning (Brown et al., 2018). Despite these fitness costs, 

al., 2018).

Taken together, these stormwater wetlands (separate to the ones studied for the frog experiments) may be 'equal-preference' ecological traps for G. pusilla, with fish equally preferring poorer quality options (Robertson and Hutto, 2006). Our results also suggest that invasive species in stormwater wetlands can cause ecological traps. G. holbrooki is frequently observed in high densities within stormwater wetlands across Melbourne (R. Coleman personal observations). Much of the work on managing ecological traps has focussed at the site scale such as improving habitat quality or reducing the attractiveness of poor quality habitats. Our results illustrate that for species like G. pusilla that are highly dispersive but not selective about habitats, a whole-of-landscape approach is necessary. This requires that we consider where wetlands are constructed relative to existing populations, which may be important for frogs also.

\section{Key considerations for managing stormwater wetlands for biodiversity}

\subsection{Stormwater wetlands can be ecological traps}

The potential for stormwater wetlands to be ecological traps was first raised in the mid1990s (Tilton, 1995), but our research provides the first empirical evidence that this is the case for both fish and frogs. Furthermore, the mechanisms causing these ecological traps were different for the two taxonomic groups. Measures of frog fitness (e.g. tadpole survival) was lower at more polluted sites (Sievers et al., 2018c), but other environmental characteristics, in particular vegetation and macrophyte cover, zooplankton (food) densities, and the invasive eastern gambusia were more important determinants of the fitness of $G$. pusilla (Brown et al., 2018; Hale et al., 2018). This highlights that stormwater wetland 
management needs to reduce the unintended consequences to native animals but also that these requirements will likely vary between species and life history stages. This is a wellknown part of wetland management (e.g. Hamer et al., 2012) but is not routine as part of stormwater wetland planning and design.

To gain a better understanding of whether the effects we observed are widespread, similar assessments are needed at a greater number of sites. Ideally, these sites would span a range of potentially influential environmental contexts, such as pollutant levels which vary according to catchment land-use (Sharley et al., 2017). It is also possible that what is an ecological trap for one species may be suitable habitat for others. For instance, there might be variability in how different species are affected by heavy metals, with some stream invertebrates (Hale et al., 2014) being more tolerant of heavy metals than frogs (Sievers et al., 2018c). Clearly there will be pollution levels that adversely affect all species but impacts on fitness at other levels is likely to be species-specific.

Only recently have studies attempted to examine inter-specific variability in the effects of ecological traps (Robertson et al., 2018), and future work exploring how similar conditions affect the fitness of different species would provide guidance to wetland managers about the need for targeted interventions for the most susceptible animals (e.g. those that are rare or threatened, that have very specific habitat requirements, or those of strategic importance such as conservation-listed species).

\subsection{Managing the effects of ecological traps in the context of urban stormwater wetlands}

Management is often based on human perceptions of good habitats for animals, typically in terms of structural elements such as land cover or vegetation type (Van Dyck, 2012). 
Managing ecological traps depends on thinking more about (1) what represents good habitat from the perspective of animals, as well as (2) if, and how, do animals recognise and prefer good habitats. Therefore, ecological traps can be managed by using this information to either improve habitat quality or reduce the attractiveness of habitats.

One of the main aspects of habitat quality in relation to stormwater wetlands is the accumulation of pollutants, which can have clear deleterious effects on frogs (Sievers et al., 2018b; Sievers et al., 2018c) and other animals. To ensure the functionality of stormwater wetlands for stormwater treatment, a key aspect is to develop schedules for inspection and maintenance (EPA, 2009b). The aim of maintenance is to preserve a desired level of performance and efficiency, and to extend the life-span of the wetland (Erickson et al., 2013) Determining the frequency that accumulated polluted sediment must be removed is important, and this can be based on sedimentation rates and the remaining capacity of treatment cells such as inlet sediment pond, or published guidelines such as the EPA Victoria Industrial waste resource guidelines for soils and sediments (EPA, 2009a). The frequency of maintenance is an important decision, given the typically high cost of sediment disposal (Sharley et al., 2017). Managing wetlands to decrease the likelihood of unintended consequences to biodiversity may require increased maintenance regimes, and so a key avenue for future work is to develop optimal stormwater wetland maintenance regimes that reduce the risk of pollutant accumulation to biodiversity i.e. what is the ideal frequency of maintenance to maintain pollutant levels below critical thresholds for certain animals? If more frequent maintenance is required, how do we assess and balance the ecological risks with the cost of sediment disposal?

A mechanistic view of animal behaviour can help identify management levers that can be used to modify behaviour and ultimately population-level processes (Blumstein and BergerTal, 2015). Understanding the habitats animals prefer and why, is an important knowledge 
gap to prevent ecological traps, but habitat selection behaviour of animals is not routinely considered in stormwater wetland management (Sievers et al., 2018a). Principles from cognition have been proposed as a useful tool to manipulate problematic behaviours by animals (Greggor et al., 2014) based on identifying the cue that animals use, and the cognitive processes underpinning this behaviour, before targeting those processes, within the constraints of the animal and the cue, and this approach may be fruitful for managing stormwater wetlands that are ecological traps.

If we can identify the specific elements of habitats that animals respond to, it may be possible to decrease the attractiveness of habitats to ameliorate ecological traps. For example, Robertson (2012) developed a set of management prescriptions to disarm an ecological trap for the Olive-sided fly catcher (Contopus cooperi) based on understanding which habitat features this species responds most strongly to. Alternatively, we may be able to attract animals into suitable habitats by changing characteristics of the environment to alter habitat selection behaviour. For example, playbacks from calling conspecifics can be used to attract birds and amphibians to breeding sites (Ward and Schlossberg, 2004). This may be difficult to implement on a broader scale but could be useful at particular wetlands. At broader scales, other measures such as planting or removing certain types of vegetation in and around the wetland may be more feasible.

Stormwater wetlands are often constructed as a series of ponds (CSIRO, 2005), with inlets initially leading to deeper sediment ponds where many pollutants settle before water moves through a series of other pools containing vegetation. Pollutant levels are likely to vary spatially throughout this series of ponds, so one possibility is to attract animals into areas where exposure to pollutants is reduced. This has been proposed as an option at landscape scales to reduce animals using particular wetlands (Sharley et al., 2017) but may also be possible within the wetland treatment train. For example, by minimising emergent or 
fringing vegetation or substituting it with alternative vegetation (e.g. deep submerged) it may discourage wildlife occupation (Sievers et al., In press) without compromising the performance of the wetland. This increased flexibility in wetland design is worth further investigation.

\subsection{Better understanding the ecological consequences of changes to wetlands}

While our work shows that some stormwater wetlands can be ecological traps, most studies examining how animals respond to changes in wetland quality rarely collect information about fitness and behaviour (Sievers et al., 2018a). Community and populationlevel metrics that are commonly used to assess wetlands provide information about whether animals are present but not whether they are able to survive, grow and reproduce. Community and population metrics are also likely to be less sensitive than measures of individual fitness (Sievers et al., 2018a). While previous work has shown that species richness and the abundance of animals can be high in stormwater wetlands (e.g. Holtmann et al., 2018), there is a need to also assess the fitness of these animals i.e. to understand the potential short-term versus long-term benefits or impacts.

Stormwater wetlands can contain a suite of different pollutants, as two recent studies from Melbourne demonstrate. In the first, Allinson et al. (2015) collected sediment samples from 24 wetlands and screened for 90 different pesticides, with 23 of these detected at least once. In the second, Sharley et al. (2017) collected sediment samples from 98 wetlands, with 13 metals recorded at all sites, and petrochemical hydrocarbons recorded at $94 \%$ of sites. Almost a third of sites had zinc values above published sediment quality thresholds. There has been extensive research on the ecotoxicology of stormwater pollutants and more work in this area is needed, especially in terms of potential interactions between different stressors, and also 
less studied chemicals. We observed lethal effects of imidacloprid at concentrations well below published $\mathrm{LC}_{50}$ values, and showed that exposed tadpoles did not avoid cues from predators (Sievers et al., 2018b). More research is needed to understand the effects of pollutants on a wide range of species, life history stages (we might predict early stages like eggs and larvae to be more susceptible for example) and potential endpoints (e.g. mortality vs. sub-lethal effects like changes in behaviour). Given that pollutants co-occur at wetlands and could interact in complex ways (e.g. Piggott et al., 2015), looking at potential interactive effects between stressors is also critical.

\subsection{Considering landscape context in wetland management}

Although it is important to demonstrate where ecological traps are present, evaluating their population level consequences is pertinent for the sustained management of urban stormwater wetlands for wildlife. For example, do ecological traps mean populations of native animals are less likely to persist? Presently, this question has been addressed mainly using models (e.g. Delibes et al., 2001; Hale et al., 2015b) rather than empirical data collection. To evaluate the ultimate ecological costs and benefits of stormwater wetlands, it is necessary to explore whether observed fitness costs affect the likelihood of species persistence.

From a regional biodiversity perspective, it is critical to understand whether the presence of stormwater wetlands within urban landscapes (that may be polluted, poor quality habitats) provides greater benefits than no or few aquatic habitats. This is an important question across cities where habitat loss and fragmentation commonly occur. Poor quality habitats may still play an important role in terms of providing connectivity to better quality habitats throughout the landscape or maintaining a persistent but sub-optimal metapopulation. It is important to 
understand the local-scale effects of stormwater wetlands (i.e. if animals colonise them, can they survive and breed?) but also how individual wetlands contribute to landscape connectivity (i.e. do they provide dispersers that can move elsewhere?). Conservation priorities are often based on the contribution of individual patches to landscape connectivity (Rubio et al., 2015), and it is important to consider stormwater wetlands in this regard. Simulation modelling has demonstrated that if habitats vary temporally in terms of quality, it is possible that regional populations can persist even if all patches are of low quality overall (population growth rate $<1$ ) i.e. all patches are low quality when considered over longer time scales but at any one time point there is sufficient variability so that some are suitable (Schreiber, 2010). This could be important for stormwater wetlands, where pollutant loads may be higher after rainfall events (Walsh et al., 2016).

For species that are highly dispersive, it will also be important to consider where stormwater wetlands are located relative to other habitats while considering the movement capacity and behaviour of different species. For instance, G. pusilla are highly dispersive and appear to have low habitat selectivity (Hale et al., 2018). Should we therefore consider building alternative high-quality habitats nearby to stormwater wetlands for the persistence of this nationally significant species? Or avoid building stormwater wetlands when possible in areas where this species occurs?

Landscape context is also an important management consideration. For example, catchment land use is likely to be a key determinant of the pollution levels within wetlands (Sharley et al., 2017), so actions undertaken at the catchment-scale to address the underlying causes of stormwater run-off might be more effective than actions at the site level (Vietz et al., 2016a). While such catchment-scale management attempts are rare and require interdisciplinary collaborations that consider the complex social-ecological aspects of urban catchments, some examples do exist (e.g. Walsh et al., 2015). For example, retaining more 
water in the upstream catchment (e.g. via water sensitive urban design methods such as biofilters, raingardens and rainwater tanks to reduce and treat run-off) reduces stormwater pollutant loads into wetlands. Alternatively, diversifying the types of wetlands that are built to include adjacent offline habitats for animals that are less likely to accumulate pollutants for animals when designing stormwater treatment wetlands.

\section{Conclusions}

Stormwater run-off is a major environmental issue for aquatic ecosystems in urban areas, and stormwater treatment wetlands can be an effective pollution management tool. However, stormwater wetlands are often used incidentally as habitats for animals. This can be beneficial for the persistence of some species in fragmented urban environments. However, we have demonstrated that there is the potential that animals that colonise these wetlands suffer deleterious impacts such as from accumulated pollutants or the presence of invasive species. To guide planning and maintenance decision-making, we have highlighted some of the key issues and management options for these wetlands so that impacts to biodiversity may be reduced. We acknowledge the preliminary nature of these recommendations and strongly advocate for a deeper understanding of the benefits and impacts of urban stormwater treatment wetlands across a broader suite of animals across both site- and regional-scales.

\section{Acknowledgements}

This work was supported by Melbourne Water and the Australian Research Council under project LP140100343. We thank the following people for attending a workshop to discuss this project, and for providing feedback on an earlier draft of this manuscript: Alison Rickard, David Reginato, Bronwen Hutchison, William Steele, Trish Grant, Birgit Jordan, Rachael 

the workshop.

\section{References}

ABS, 2018. http://www.abs.gov.au/ausstats/abs@.nsf/mf/3218.0.

Al-Rubaei, A.M., Engstrom, M., Viklander, M., Blecken, G.T., 2017. Effectiveness of a 19-

Year Old Combined Pond-Wetland System in Removing Particulate and Dissolved Pollutants. Wetlands 37, 485-496.

Allinson, G., Zhang, P., Bui, A., Allinson, M., Rose, G., Marshall, S., Pettigrove, V., 2015. Pesticide and trace metal occurrence and aquatic benchmark exceedances in surface waters and sediments of urban wetlands and retention ponds in Melbourne, Australia. Environmental Science and Pollution Research 22, 10214-10226.

Battin, J., 2004. When good animals love bad habitats: Ecological traps and the conservation of animal populations. Conserv Biol 18, 1482-1491.

Blumstein, D.T., Berger-Tal, O., 2015. Understanding sensory mechanisms to develop effective conservation and management tools. Curr. Opin. Behav. Sci. 6, 13-18.

Brown, T.R., Coleman, R., Swearer, S.E., Hale, R., 2018. Behavioural responses to, and fitness consequences from, an invasive species are life-stage dependent in a threatened native fish. Biological Conservation 228, 10-16.

427 Brunelli, E., Bernabò, I., Berg, C., Lundstedt-Enkel, K., Bonacci, A., Tripepi, S., 2009.

428 Environmentally relevant concentrations of endosulfan impair development, metamorphosis 429 and behaviour in Bufo bufo tadpoles. Aquatic Toxicology 91, 135-142. 
430 Chin, A., 2006. Urban transformation of river landscapes in a global context. Geomorphology $79,460-487$.

432 Cody, M.L., 1985. Habitat selection in birds. Academic Press, Orlando, FL, USA.

433 Coleman, R.A., 2014. Conservation of the dwarf galaxias, Galaxiella pusilla (Mack 1936)

434 (Teleostei: Galaxiidae), a threatened freshwater fish from south-eastern Australia, School of 435 BioSciences. PhD Dissertation, University of Melbourne, Australia.

436 Coleman, R.A., Hoffmann, A.A., Raadik, T.A., 2015. A review of Galaxiella pusilla (Mack)

437 (Teleostei: Galaxiidae) in south-eastern Australia with a description of a new species. 438 Zootaxa 4021, 243-281.

439 Coleman, R.A., Raadik, T.A., Pettigrove, V., Hoffmann, A.A., 2017. Taking advantage of 440 adaptations when managing threatened species within variable environments: the case of the 441 dwarf galaxias, Galaxiella pusilla (Teleostei, Galaxiidae). Marine and Freshwater Research $44268,175-186$.

443 CSIRO, 2005. WSUD Engineering Procedures : Stormwater. CSIRO Publishing, Victoria, 444 Australia.

445 Delibes, M., Gaona, P., Ferreras, P., 2001. Effects of an attractive sink leading into 446 maladaptive habitat selection. The American Naturalist 158, 277-285.

447 EPA, 2009a. Soil hazard categorisation and management, industrial waste resource 448 guidelines. Environmental Protection Authority, Melbourne. 
450 Erickson, A.J., Weiss, P.T., Gulliver, J.S., 2013. Maintenance of stormwater treatment 451 practices, Optimizing Stormwater Treatment Practices. Springer, pp. 265-283.

452 Ficken, K., Byrne, P.G., 2013. Heavy metal pollution negatively correlates with anuran 453 species richenss and distribution in south-eastern Australia. Austral Ecology 38, 523-533.

454 Gallagher, M.T., Snodgrass, J.W., Brand, A.B., Casey, R.E., Lev, S.M., Van Meter, R.J., 455 2014. The role of pollutant accumulation in determining the use of stormwater ponds by 456 amphibians. Wetlands Ecology and Management 22, 551-564.

457 Greggor, A.L., Clayton, N.S., Phalan, B., Thornton, A., 2014. Comparative cognition for 458 conservationists. Trends Ecol. Evol. 29, 489-495.

Hale, R., Coleman, R., Pettigrove, V., Swearer, S.E., 2015a. Identifying, preventing and 460 mitigating ecological traps to improve the management of urban aquatic ecosystems. Journal 461 of Applied Ecology 52, 928-939. behaviour to manage ecological traps for a threatened freshwater fish. Ecosphere 9, e02381. physicochemistry and sediment contamination on Chironomus tepperi (Skuse) survival, growth and development: A boosted regression tree approach. Aquatic Toxicology 152, 6673. responses to multiple stressors and multiple stimuli. Ecol Evol 7, 38-47. 
470 Hale, R., Swearer, S.E., 2017. When good animals love bad restored habitats: how

471 maladaptive habitat selection can constrain restoration. Journal of Applied Ecology 54, 1478-

4721486

473 Hale, R., Treml, E.A., Swearer, S.E., 2015b. Evaluating the metapopulation consequences of 474 ecological traps. Proc. R. Soc. Lond. B Biol. Sci. 282, 20142930.

475 Halfwerk, W., Slabbekoorn, H., 2015. Pollution going multimodal: the complex impact of the 476 human-altered sensory environment on animal perception and performance. Biology Letters $477 \quad 11,20141051$.

478 Hamer, A.J., Parris, K.M., 2011. Local and landscape determinants of amphibian 479 communities in urban ponds. Ecol. Appl. 21, 378-390.

480 Hamer, A.J., Smith, P.J., McDonnell, M.J., 2012. The importance of habitat design and 481 aquatic connectivity in amphibian use of urban stormwater retention ponds. Urban 482 Ecosystems 15, 451-471.

483 Hassall, C., Anderson, S., 2015. Stormwater ponds can contain comparable biodiversity to 484 unmanaged wetlands in urban areas. Hydrobiologia 745, 137-149.

485 Holtmann, L., Juchem, M., Bruggeshemke, J., Mohlmeyer, A., Fartmann, T., 2018.

486 Stormwater ponds promote dragonfly (Odonata) species richness and density in urban areas.

487 Ecol. Eng. 118, 1-11.

488 Holtmann, L., Philipp, K., Becke, C., Fartmann, T., 2017. Effects of habitat and landscape 489 quality on amphibian assemblages of urban stormwater ponds. Urban Ecosystems 20, 12494901259. 
Horvath, G., 1995. Reflection polarization patterns at flat water surfaces and their relevance

492 for insect polarization vision. Journal of Theoretical Biology 175, 27-37.

493 Horvath, G., Bernath, B., Molnar, G., 1998. Dragonflies find crude oil visually more 494 attractive than water: Multiple-choice experiments on dragonfly polarotaxis.

495 Naturwissenschaften 85, 292-297.

IUCN, 2015. The IUCN Redlist for Threatened Species. International Union of Conservation 497 of Nature, www.iucnredlist.org.

Kentula, M.E., Gwin, S.E., Pierson, S.M., 2004. Tracking changes in wetlands with urbanization: Sixteen years of experience in Portland, Oregon, USA. Wetlands 24, 734-743. wetlands for stormwater management in the UK: a concise review. Civil Engineering and Environmental Systems 32, 251-268. runoff. Critical Reviews in Environmental Science and Technology 42, 2153-2214.

Moore, H., Chivers, D.P., Ferrari, M.C., 2015. Sub-lethal effects of Roundup ${ }^{\mathrm{TM}}$ on tadpole anti-predator responses. Ecotoxicology and environmental safety 111, 281-285. artificial wetlands in an Australian urban landscape. Hydrobiologia 716, 131-146.

Piggott, J.J., Townsend, C.R., Matthaei, C.D., 2015. Reconceptualizing synergism and antagonism among multiple stressors. Ecology and Evolution 5, 1538-1547. 
Pyke, G.H., 2008. Plague minnow or mosquito fish? A review of the biology and impacts of introduced Gambusia species. Annual Review of Ecology Evolution and Systematics 39, 171-191. and the cause of amphibian abnormalities. Ecological Monographs 80, 423-440.

Robertson, B.A., 2012. Investigating targets of avian habitat management to eliminate an ecological trap. Avian Conservation and Ecology 7.

Robertson, B.A., Chalfoun, A.D., 2016. Evolutionary traps as keys to understanding behavioral maladapation. Curr. Opin. Behav. Sci. 12, 12-17.

Robertson, B.A., Hutto, R.L., 2006. A framework for understanding ecological traps and an evaluation of existing evidence. Ecology 87, 1075-1085. Hetterich, I., Horváth, G., 2018. Susceptibility to ecological traps is similar among closely related taxa but sensitive to spatial isolation. Animal Behaviour 135, 77-84.

Robertson, B.A., Rehage, J.S., Sih, A., 2013. Ecological novelty and the emergence of evolutionary traps. Trends in Ecology and Evolution 28, 552-560.

527 Rubio, L., Bodin, Ö., Brotons, L., Saura, S., 2015. Connectivity conservation priorities for individual patches evaluated in the present landscape: how durable and effective are they in the long term? Ecography 38, 782-791. 
532 Schreiber, S.J., 2010. Interactive effects of temporal correlations, spatial heterogeneity and 533 dispersal on population persistence. Proc. R. Soc. Lond. B Biol. Sci., rspb20092006.

534 Schulz, C., Gelbrecht, J., Rennert, B., 2003. Treatment of rainbow trout farm effluents in 535 constructed wetland with emergent plants and subsurface horizontal water flow. Aquaculture $536217,207-221$.

537 Sharley, D.J., Sharp, S.M., Marshall, S., Jeppe, K., Pettigrove, V.J., 2017. Linking urban land 538 use to pollutants in constructed wetlands: Implications for stormwater and urban planning. 539 Landscape and Urban Planning 162, 80-91.

540 Sievers, M., Hale, R., Parris, K.M., Swearer, S.E., 2018a. Impacts of human-induced 541 environmental change in wetlands on aquatic animals. Biological Reviews 93, 529-554.

542 Sievers, M., Hale, R., Swearer, S.E., Parris, K.M., 2018b. Contaminant mixtures interact to 543 impair predator-avoidance behaviours and survival in a larval amphibian. Ecotoxicology and 544 Environmental Safety 161, 482-488.

545 Sievers, M., Hale, R., Swearer, S.E., Parris, K.M., In press. Occupancy of polluted wetlands 546 is a risk to conserving frogs in urban landscapes. Conserv Biol.

547 Sievers, M., Parris, K.M., Swearer, S.E., Hale, R., 2018c. Stormwater wetlands can function 548 as ecological traps for urban frogs. Ecol. Appl. 28, 1106-1115.

549 Snodgrass, J.W., Casey, R.E., Joseph, D., Simon, J.A., 2008. Microcosm investigations of 550 stormwater pond sediment toxicity to embryonic and larval amphibians: variation in 551 sensitivity among species. Environmental Pollution 154, 291-297. 
552 Soanes, K., Sievers, M., Chee, Y.E., Williams, N.S.G., Bhardwaj, M., Marshall, A.J., Parris,

553 K.M., In press. Correcting common misconceptions to inspire conservation action in urban

554 environments. Conserv Biol.

555 Søberg, L.C., Vollertsen, J., Blecken, G.-T., Nielsen, A.H., Viklander, M., 2016.

556 Bioaccumulation of heavy metals in two wet retention ponds. Urban Water Journal 13, 697-

$557 \quad 709$.

558 Stephansen, D.A., Nielsen, A.H., Hvitved-Jacobsen, T., Pedersen, M.L., Vollertsen, J., 2016.

559 Invertebrates in stormwater wet detention ponds-Sediment accumulation and

560 bioaccumulation of heavy metals have no effect on biodiversity and community structure.

561 Science of the Total Environment 566, 1579-1587.

562 Tilton, D.L., 1995. Integrating wetlands into planned landscapes. Landscape and Urban

563 Planning 32, 205-209.

564 Tixier, G.T., Lafont, M., Grapentine, L., Rochfort, Q., Marsalek, J., 2011. Ecological risk

565 assessment of urban stormwater ponds: literature review and proposal of a new conceptual

566 approach providing ecological quality goals and the associated bioassessment tools.

567 Ecological Indicators 11, 1497-1506.

568 Tuomainen, U., Candolin, U., 2011. Behavioural responses to human-induced environmental

569 change. Biological Reviews 86, 640-657.

570 Van Dyck, H., 2012. Changing organisms in rapidly changing anthropogenic landscapes: the

571 significance of the Umwelt'-concept and functional habitat for animal conservation. Evol.

572 Appl. 5, 144-153. 
573 Vietz, G.J., Rutherfurd, I.D., Fletcher, T.D., Walsh, C.J., 2016a. Thinking outside the

574 channel: Challenges and opportunities for protection and restoration of stream morphology in

575 urbanizing catchments. Landscape and Urban Planning 145, 34-44.

576 Vietz, G.J., Walsh, C.J., Fletcher, T.D., 2016b. Urban hydrogeomorphology and the urban

577 stream syndrome: Treating the symptoms and causes of geomorphic change. Progress in

578 Physical Geography 40, 480-492.

579 Walsh, C.J., Booth, D.B., Burns, M.J., Fletcher, T.D., Hale, R.L., Hoang, L.N., Livingston, 580 G., Rippy, M.A., Roy, A.H., Scoggins, M., Wallace, A., 2016. Principles for urban

581 stormwater management to protect stream ecosystems. Freshwater Science 35, 398-411.

582 Walsh, C.J., Fletcher, T.D., Bos, D.G., Imberger, S.J., 2015. Restoring a stream through 583 retention of urban stormwater runoff: a catchment-scale experiment in a social-ecological 584 system. Freshwater Science 34, 1161-1168.

585 Walsh, C.J., Roy, A.H., Feminella, J.W., Cottingham, P.D., Groffman, P.M., Morgan, R.P., 586 2005. The urban stream syndrome: current knowledge and the search for a cure. Journal of 587 the North American Benthological Society 24, 706-723.

588 Ward, M.P., Schlossberg, S., 2004. Conspecific attraction and the conservation of territorial 589 songbirds. Conserv Biol 18, 519-525.

590 WHO, 2017.

591 http://www.who.int/gho/urban_health/situation_trends/urban_population_growth/en/.

592 Wong, B.B.M., Candolin, U., 2015. Behavioral responses to changing environments. Behav. 593 Ecol. 26, 665-673. 
594 Zala, S.M., Penn, D.J., 2004. Abnormal behaviours induced by chemical pollution: a review 595 of the evidence and new challenges. Animal Behaviour 68, 649-664. 